of mountains is calculated, and to which barometrical readings are reduced.

This assumption, however, is called in question by several mathematicians, who allege that the sea-level is by no means that of a regular spheroid, as is generally supposed, but may vary many hundreds of feet in level even along the same parallel of latitude, quite independently of the temporary action of winds or of ocean currents.

According to the law of gravitation, all substances attract one another with a force proportional to their masses. A continent of land will therefore exert an attractive influence upon the sea, and cause it to rise upon its 'shores to a height which will vary according to the mass of land that causes the attraction, and may amount, it is said, to as much as 1000 metres above the level to which the sea attains in mid-ocean. This extraordinary result is deduced by $\mathrm{Ph}$. Fischer from a discussion of pendulumobservations, and somewhat similar conclusions are arrived at by Listing and Heinrich Bruns.

Founding upon these observations, a German geologist, Dr. Penck, has proposed an explanation of the phenomena presented by the raised beaches, and other tokens of oscillation in the sea. level, which are so conspicuous during the glacial period. If the land has the property of thus drawing the sea towards it in proportion to its mass, it follows that anything which adds to that mass will increase the effect, and thus a great thickness of glacier-ice laid upon a continent, will draw the water towards it, and raise the sea-level in its immediate vicinity; and, according as the ice increases or diminishes, so will the level of the sea rise or fall in proportion. Moreover, the altitude of the seabeach may vary considerably, it is said, along the border of one and the same continent, by reason of the varying thickness of the ice in different parts. In this way it is conceived an explanation is found for the fact that in Norway the old terraces and seabeaches do not coincide in level, but vary in altitude at places not very far distant from one another. The action of the ice may in short be so localised that its attractive force will vary consideratily along the same line of coast.

These views are certainly somewhat different from those that have hitherto prevailed in regard to the regularity of the sea-level. If there is such a very great difference in the height to which the surface of the sea may attain in different places, the barometer should give more indication of it than it seems to do. Nevertheless, it is to be desired that every means should be taken to ascertain the relative beight of the sea in various places so chosen as to test the truth of the views I have mentioned. The apparent connection between glaciation and submergence is now attracting notice in various quarters. Dr. Penck maintain that shifts in the relative level of sea and land go hand in hand with oscillations in the glaciation. In 1865 I called attention to this connection, and suggested what seemed to me to be a possible explanation of it (see Fourn. of the Geol. Soc. vol. xxi. p. 178 ).

Penck's views, it will be seen, are somewhat different from those of Adbemar and Croll, to which be points out sever 1 objections. His memoir is entitled "Schwankungen des Meeresspiegels," and appears in the Fahrbuch der Geograph. Gesellschaft zu München, Bd, vii. I882.

Ellon, Aberdeenshire, July $3 \mathbf{r}$

T. F. JAMIESON

\section{Voice in Lizards}

THE above heading in NATURE, vol. xxvi. p. 29, rather surprises me, as though voices in lizards were a recent discovery. The loud and plaintive "gui-gui-gui" made by the large land lizard of that name, has been well known to me for the last seventeen years, and is of course well known to every Assamese. The call is always heard in twilight, in the depths of the forest, and when once heard is not mistakable for that of any other animal. It is plain, monotonous, loud, and repeated with two second intervals some eight or ten times, when there is a pause of about two minutes, and it is repeated. For those who do not understand the Hunterian system of spelling I would write it gooee-gooee, the oo most prolonged. The gui is about 3 to $3 \frac{1}{2}$ feet long-from snout to tip of tail-which latter exceeds the body and head. Colour grey-green, with clear yellow scales here and there-at times grouped-and that gives a mottled appearance. The tail has a double row of sharp scale-: pines along its crest, and if suddenly lashed can cut the skin of any bare-legged bystanders.
It lives in holes under, or in, tree stems, often as.high up as 30 or 40 feet. The flesh is eaten and prized, the skin used as the membrane in some kinds of guitars. There seem several kinds, one of 3 or $3 \frac{1}{2}$ feet, another larger-both land lizards-a still larger kind frequents the rivers, up to 6 feet or more in length. It hisses like the larger snakes, and the peculiar call that gives it the name "gui," can be heard in still forest I should say a mile; one that repeats this monotonous call every evening is loud enough to be an annoyance at times, though it is over 500 yards off.

Sibsagar, Assam

S. E. PEAL

\section{Halo}

ABout 2 p.m. to-day a remarkable halo was visible here. The sky was partially covered with light cirrus clouds, and some small fleecy drift was rapidly moving from the north-west at a low altitude. I saw a bright bow at about $45^{\circ}$ from the sun nearly due north, extending over a clear portion of the sky; this gradually extended till it formed a circle with the sun in the most southern point of its circumference. The width of the bow was rather greater than the diameter of the sun, the whole circle being, as near as I could judge, $45^{\circ}$ or $50^{\circ}$ in diameter. It was brilliantly white, brighter than the white of any clouds in the neighbourhood; it lasted perhaps fifteen minutes, and gradually broke up and fadef. I could see no other interesting halo nor any appearance of parbelia.

Tynehead, Somerset, July 25

\section{THE ELECTRIC PROPERTIES OF FLAMES}

$T \mathrm{HE}$ electric properties of flames bave often invited the investigation of physicists, but the obscurity and contradictory nature of some of the phenomena have been such that in spite- of a large number of researches no complete account of these properties has hitherto been given. Most of these researches are enumerated in a paper contributed by Prof. Holtz to Carl's Repertorium last year; but though Holtz has himself added to our knowledge of the electrical property of flames by his researches on the behaviour of flames when employed as electrodes, he left much yet to be investigated in this department.

The latest contribution to our knowledge of the subject appears in the current volume of Wiedemann's Annalen der Physik und Chemie, from the joint pens of Herren Dr. Julius Elster and Hans Geitel. As the results of their investigations go far to clear up some of the points which have hitherto been obscure or contradictory, some account of these investigations will probably not be unacceptable to the readers of NATURE.

The chief theories that have been advanced from time to time in explanation of the electrical properties of flames may be reckoned as three in number.

I. Pouillet in 1827 propounded the suggestion that the electricity of flame is due to the process of combustion as such, and therefore presumably analogous to the electrification observed by Volta to result when a burning coal or pastille is placed upon the cap of an electroscope.

2. Matteucci, in 1854 , explained the phenomena by supposing that the flame acted upon the two metal electrodes (employed to test its electrification) as an electrolyte ; in fact, that it acted as the acid between the two metallic plates of a voltaic cell ; a view which practically agrees with that earlier propounded by Hankel.

3. Buff suggested that the explanation was to be sought in a thermo-electric difference between the two electrodes.

Sir William (Mr. Justice) Grove had shown moreover that when a platinum wire is bent so that one end of it stands in the tip of a flame, while the other is immersed in the flame near its base, a current of electricity is set up in the wire. This phenomenon might at first sight be thought to agree with an observation of Hankel, that a flame is "polarised" longitudinally ; that is to say, Hankel found there is a difference of potential between the tip and the base of a flame, and this difference of poten- 
tial is, of course, equivalent to an electromotive force acting along the flame. The want of concord amongst different observers, not only as to the cause of the electrical properties of flame, but even as to what those properties were, is most singular. Probably a great part of it arises from the omission to notice one very important point, namely, the part played in these electrical phenomena by the sheet or mantle of hot air surrounding the flame externally. Almost all these observers have used as their instrument of investigation either a coarse gold-leaf electroscope, or else a galvanometer. The want of sensitiveness and accuracy in the former instrument when applied to small differences of potential, makes the former unsuitable ; whilst the high resistance offered by the flame itself to the passage of electricity renders the use of the latter inadvisable.

In beginning their investigation, therefore, Messrs. Elster and Geitel bethought themselves of Sir W. Thomson's quadrant electrometer as admirably suited for delicate and quantitative experiments of the kind in hand,

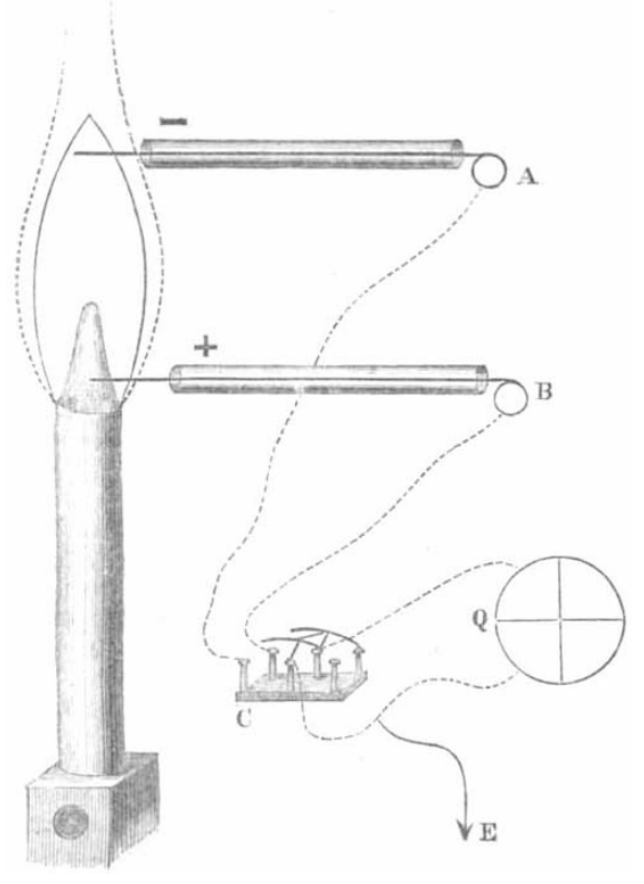

Fig. 8.

and with this instrument they set themselves to investigate the correctness or otherwise of that which previous observers had announced.

Their apparatus was set up as follows:-To keep the needle of the electrometer at a constant charge, it was connected with one pole of a Zamboni's dry pile consisting of 2400 pairs of disks, the other pole being joined to "earth." The electrometer thus arranged was very sensitive, a difference of potential of a single Daniell's cell producing a deflexion of I 2 degrees upon the scale of the instrument. One pair of quadrants was as usual put to "earth," and asuitable commutator (c in Fig. I) was interposed between the electrometer and the flameapparatus. Experiments were made on the flames of Bunsen burners and of spirit-lamps, both well insulated. A small Bunsen burner specially adapted for this purpose was constructed out of a piece of glass tubing 4 millimetres wide. Fig.. I shows the manner of exploring the flame. One electrode, A, consisting of a platinum wire inclosed in a glass tube from which the end protruded, was inserted in the tip of the flame. Another electrode,
$B$, of similar kind was fixed so as to pass into the base of the flame. Two points were revealed by the first experiments made :

I. That when set in this fashion the tip was usually electrically negative, as compared with the base of the flame, as Hankel had said, but that sometimes the reverse appeared to be the case.

2. That when the lower electrode was kept fixed, and the upper one was moved to different heights, the potential anywhere within the interior of the flame was the same, being I'O4 times that of one Daniell's cell when the electrodes were I millimetre apart, and the same when they were 20 millimetres apart.

If, as Hankel expresses it, a flame were "polarised" longitudinally, cross-sections taken horizontally across the flame should be equipotential surfaces. This is true if the two platinum electrodes $\mathrm{A}$ and $\mathrm{B}$ are both right within the flame. Whether at the same level or not, when both are completely within the flame they are practically at the same potential-neither of them positive or negative relatively to the otber. But if one of the electrodes is displaced to one side, a difference of potential is immediately observed, and this difference is very great if (as in Fig. I) one electrode passes no further than into the external mantle of hot air.

To examine more particularly the part played by this external mantle was the next point. It will be observed from Fig. I, that the two electrodes were so chosen that the protruding portion of the platinum wire was equal in length to the width of the flame from side to side. As remarked above, when both were completely immersed side by side in the flame, they showed no electrical difference; but when either of them was moved into the
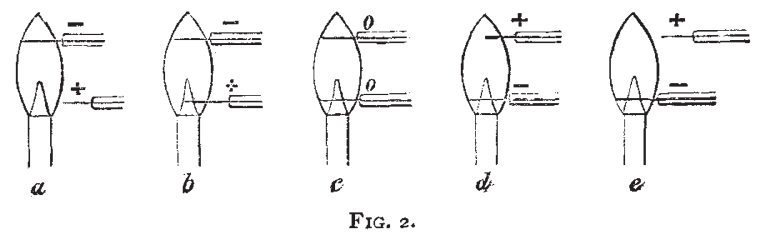

surrounding sheet of hot air, it immediately showed itself positive to the other one. The maximum difference of potential was observed when the electrodes occupied the relative positions shown in Fig. 2, $a$, where the electrode $B$ is about half a millimetre outside the flame. When $B$ was pushed in to the position shown in Fig. 2, b, the potential fell to less than half what it was before. When pushed completely in, as in Fig. 2, c, the two electrodes were so nearly alike, that the difference of potential between them was less than the hundredth part of that of a single Daniell's cell. The upper electrode, A, was now gradually removed. When it reached the position shown in Fig. $2, d$, it was decidedly positive relatively to $\mathrm{B}$, and when it was placed as in Fig. $2, e$, its negative potential was almost as great as its positive potential had been in the first position. The potential of A relatively to $B$ is given in the following table for the five positions :-

$$
\begin{aligned}
& \text { a. E.M.F. was - I'29 of I Daniell. } \\
& \text { b. }, \text {, }-0.46 \text {, } \\
& \begin{array}{llll}
c . & \text { " } & -0.009 & \text {, } \\
\text { c. } & & +0.65
\end{array} \\
& \begin{array}{lll}
\text { d. } & \text { " } & +0.65
\end{array}
\end{aligned}
$$

To put the matter into words: As long as either of the electrodes is outside the flame and the other inside, the outside one is positive and the inside one negative. The film of hot air outside the flame is always electrically positive, and the flame inside relatively negative.

The same result was obtained by these experimenters with flames of spirit-lamps and with ordinary gas and candle flames. More curious still, when air was made to 
burn with a flame in an atmosphere of coal-gas the very same phenomena are observed, the hot coal-gas being positive relatively to the air-flatne. All these flames showed a potential varying from about $I \frac{1}{2}$ to $I_{4}^{\frac{3}{4}}$ times that of a Daniell's cell. The flame of bisulphide of carbon gave a lower result, and so did a magnesium flame. The introduction of any salt of a metal-such as chloride of potassium-into the flame lowered the potential.

Moreover when wires of other metals were employed the differences of potential were not the same as before. Whilst the lower electrode of platinum remained, the upper electrode was replaced by a copper wire when the potential rose to 2 Daniell's cells. With aluminium it was equal to 3 , and with magnesium to $3^{* 2}$ Daniell's. Using a lump of clean sodium as electrode the potential even rose to five times the Daniell cell.

Using as a fluid electrode a drop of water at the end of a capillary tube similar results were obtained, though the differences of potential were smaller.

These experiments corroborate the suggestion that the flame acts like the acids between the poles of a batterycell, or that the action is an "electrolytic" one.

Messrs. Elster and Geitel succeeded in joining electrically together the flames of twenty-five spirit-lamps, by the device of causing a curved piece of platinum wire to lead from the base of one flame to the tip of the next, and another piece of wire from the base of this to the tip of the succeeding one, and so on. This "flame-battery" of course had a potential twenty-five times as great as that of one flame. But it would not yield much current, owing to the enormous internal resistance of the flames themselves.

Another most important series of researches was then undertaken to investigate whether, without any flame or any products of combustion, a difference of potential could be observed between a red-hot platinum wire and a cold platinum wire whose tip was immersed in the currents of heated air that rose from the former. 'This was accomplished by using as one electrode a thin piatinum wire heated to redness by passing through it the current of a battery. And here, without any flame, a difference of potential of about one and a half of a Daniell's cell was found, the upper electrode being positive, relatively to the glowing one. From this experiment, which was confirmed in a variety of ways, it appears that a flame is not in itself a source of electrification at all. Messrs. Elster and Geitel therefore regard the electrification as a thermo-electric phenomenon; though they use this term in a slightly different sense from that in which it is used in the text-books.

They conclude, therefore, that the production of electrification by flames is (I) independent of the size of the flame; (2) dependent on the nature and state of surface of the electrodes; (3) dependent on the nature of the gases that are burning in the flame; and (4) dependent on the state of ignition of the electrodes.

They therefore regard Pouillet's theory as being wrong, whilst the theories of Matteucci (and Hankel) and of Buff are both, so far as they go, correct. If this so-called thermo-electric origin of the electrification be the true one it is a very important fact indeed; and, as these able experimenters say, will probably explain the back-electromotive force which is observed in the voltaic arc. This is not the least interesting point in this very interesting research.

S. P. T.

THE METEOROLOGY OF ICELAND DURING THE WINTER AND SPRING OF 1881-82

THE observations made last winter by Mr. Thorlacius, observer for the Scottish Meteorological Society at Stykkisholm, Iceland, have been received by the Society, and they are of the greatest interest in connection with the unexampled mild weather which prevailed in this country for the five months ending March. The mean pressures, for these five months, at $32^{\circ}$ and sea level, were respectively $29^{\circ} 201$, $29^{\circ} 14^{\circ}, 29^{\circ} 295^{\prime}, 29^{\circ} 47$ I , and $29^{\circ} 25^{\circ}$ inches, the mean of these months being thus only 29.273 inches. In London the mean of the same months was $30^{\circ} 123$ inches, or 0.850 inch higher than that of Stykkisholm. The means for these two places for the twenty-four years ending with I880 are for London $29^{\circ} 94^{8}$ inches, and Stykkisholm 29.552 inches, the difference being 0.396 inch, or less than half the difference during the winter of I88I-82. The greatest difference occured in January, the mean pressure for which month in London was 30.365 inches, and at

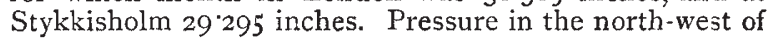
Iceland was thus $\mathrm{I} \cdot 070$ inch less than in London.

On January I4 the pressure at Greenwich was 30.572 inches, and the maximum temperature $42^{\circ} .4$, but at Stykkisholm on the same day temperature rose to $46^{\circ} 5$, with a storm of wind from the south, and pressure was as low as 28.290 inches, being 2.282 inches lower than at Greenwich. At Greenwich pressure rose at Io a.m. of the 18 th to $30^{\circ} 973$ inches, the maximum temperature being $34^{\circ} \cdot 2$; but at Stykkisholm pressure on the same day was only $29^{\circ} 466$ inches, the maximum temperature rose to $46^{\circ} .5$, and a storm of great violence from the south set in at noon and lasted till $6 \mathrm{a} . \mathrm{m}$. of the following day.

During the five months of high temperature in the British Islands the following winds prevailed less than the average of previous years, viz. W. 4 , N. I, N.E. 6, and E. 8 days; but winds from S.E. were 2, S. 7, and S.W. I4 days above the average. Hence during the winter of I $88 \mathrm{I}-82$ atmospheric pressure was not only much under the mean in the north-west of Iceland, but the great depression, which is one of the most prominent features of the meteorology of the northern hemisphere in the winter months, was, as indicated by $2 \mathbf{I}$ days' greater prevalence of S. and S.W. winds, situated considerably to the north-west of its usual position. Very low mean pressures for the winter months are of frequent occurrence in Iceland, but it is seldom that they continue uninterruptedly low for five months in succession. Thus, since Mr. Thorlacius began his observations in I845, mean pressure was nearly as low only on three other winters, viz., the winters of $\mathrm{I} 847-48, \mathrm{I} 85^{\circ} \cdot 5 \mathrm{r}$, and $\mathrm{I} 862-63$, when the mean pressures of these five months were respectively $29^{\circ} 308^{\prime}, 29^{\circ} 330$, and $29^{\prime} 3$ Io inches.

The weather underwent a complete change about the middle of March, when S. and S.W. winds nearly ceased and a high mean atmospheric pressure ruled, with repeated cyclonic disturbances passing to the southward of Stykkisholm, and involving Iceland in a succession of violent north-easterly storms of wind, which broke up the Arctic ice to the north, drove it southward, and stranded it on the north and east shores of the island. In these circumstances the weather became unusually inclement and unseasonable, and Mr. Thorlacius reports that no equally severe and disastrous spring has occurred there within the memory of any one living. About Easter all the food for horses, sheep, and cattle had been used up, and these animals died in great numbers. In his parish alone, 62 horses, 1700 sheep and swine, and 7 cows perished, causing a direct loss of $1220 l$., and the population has been brought face to face with a serious famine.

Though the Government is taking every measure in its power to mitigate the calamity, the prospect is most gloomy. Besides this, all, or nearly all, of the lambs have died, and owing to the great cold and want of rain, grass has scarcely yet begun to grow, the sea-ice still (July I) surrounds the entire north and east of the island in immense masses, and no ship can get through it to any of the harbours of these coasts. On the north coast the ice drove ashore about fifty large whales, of which the smallest is said to be forty-five feet in length, which proved an unexpected relief to the poor peasantry, and even to the proprietors of the coast districts. 